This item was submitted to Loughborough's Research Repository by the author.

Items in Figshare are protected by copyright, with all rights reserved, unless otherwise indicated.

\title{
Lecturers' perspectives on the use of a mathematics-based computer-aided assessment system
}

\section{PLEASE CITE THE PUBLISHED VERSION}

http://dx.doi.org/10.1093/teamat/hrt008

\section{PUBLISHER}

(C) The Author. Published by Oxford University Press on behalf of The Institute of Mathematics and its Applications

\section{VERSION}

AM (Accepted Manuscript)

\section{LICENCE}

CC BY-NC-ND 4.0

\section{REPOSITORY RECORD}

Broughton, Stephen J., Carol L. Robinson, and Paul Hernandez-Martinez. 2019. "Lecturers' Perspectives on the Use of a Mathematics-based Computer-aided Assessment System". figshare.

https://hdl.handle.net/2134/12225. 
This item was submitted to Loughborough's Institutional Repository (https://dspace.lboro.ac.uk/) by the author and is made available under the following Creative Commons Licence conditions.

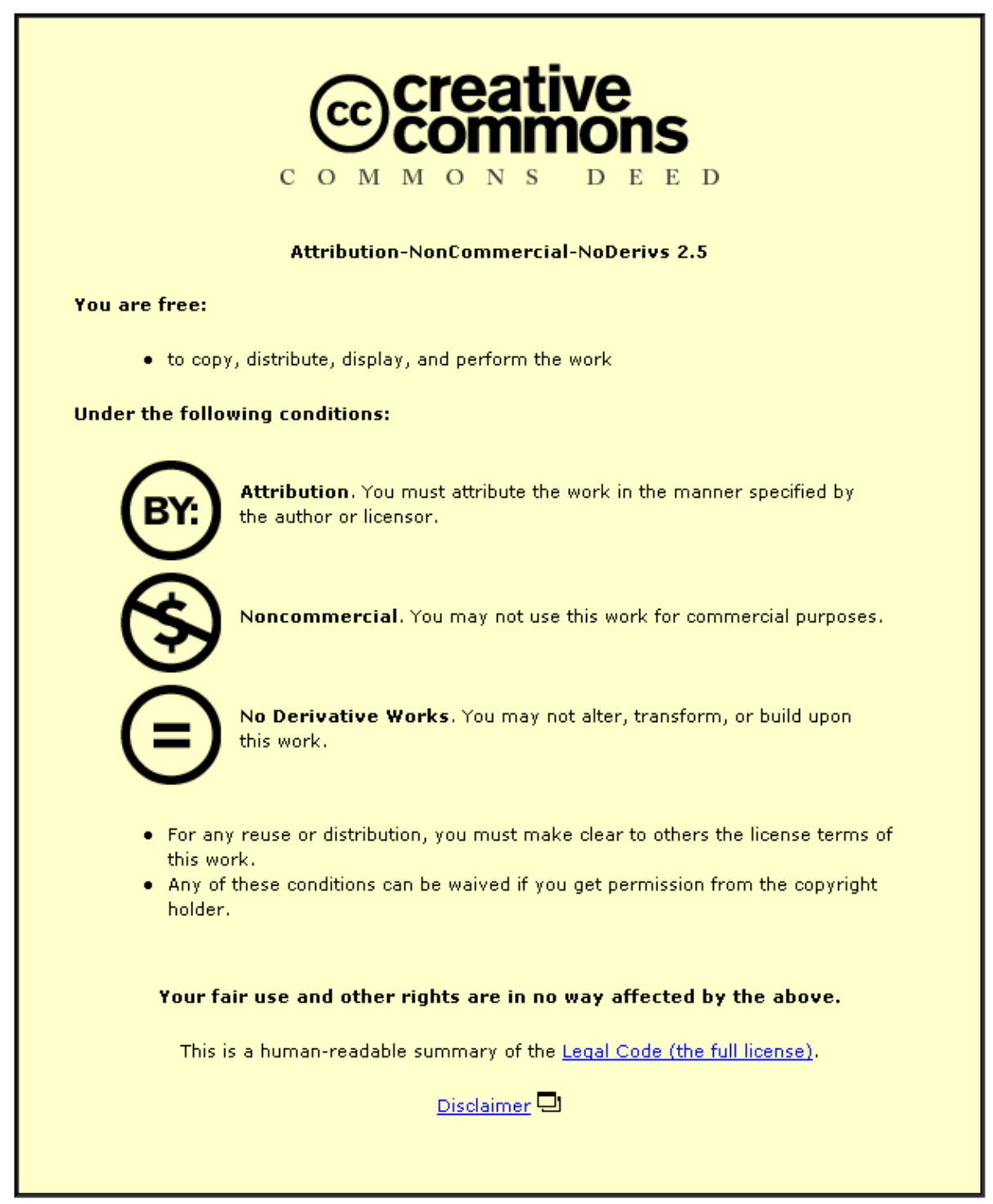

For the full text of this licence, please go to: http://creativecommons.org/licenses/by-nc-nd/2.5/ 


\title{
Lecturers' perspectives on the use of a mathematics-based computer-aided assessment system
}

\author{
Stephen Broughton, Carol L. Robinson, Paul Hernandez-Martinez \\ Mathematics Education Centre, Loughborough University, United Kingdom
}

\begin{abstract}
Computer-aided assessment (CAA) has been used at a university with one of the largest mathematics and engineering undergraduate cohorts in the UK for more than ten years. Lecturers teaching mathematics to first year students were asked about their current use of CAA in a questionnaire and in interviews.

This paper presents the issues that these lecturers faced as they made use of this assessment tool. Lecturers explained how they attempted to overcome these issues. The findings show that while the lecturers were happy to use the CAA system because it is efficient and timesaving, there were concerns that it might not always be beneficial for students. The bases for lecturers' concerns were that some students developed tendencies to depend on the feedback to complete assessments and to develop procedural, context-dependent strategies for solving problems.
\end{abstract}

\section{Introduction}

Computer-aided assessment (CAA) has become a popular and efficient method for assessing large cohorts of students. There are many reasons why CAA is so keenly adopted: it allows more frequent assessments covering more material, providing more feedback while reducing marking load - among other benefits suggested by Bull and McKenna (2003).

In the last twenty years, several CAA systems have been developed to capture these benefits in the teaching of mathematics in higher education - including STACK (Sangwin 2006) and Mathletics (Gill and Greenhow 2007). The HELM project (2006) was a joint development, between several UK universities, of learning materials to help engineers learn mathematics - including a CAA system based upon the QuestionMark Perception assessment management system (Harrison et al. 2007). A separate bank of questions designed to be used on a similar system, but for mathematics students, was developed concurrently. Hereafter, both the HELM CAA and the CAA developed for mathematics students will be described as "the CAA system".

Since the start of the development of the HELM project ten years ago, there has been a call for further research on the use of CAA with students. Conole and Warburton (2005) suggested that further research on the teaching, learning and assessment outcomes of CAA would be welcome. Miller (2009) added that research is desirable to explore how students use both the formative and the summative aspects of CAA simultaneously.

In light of these calls for research, this study serves as a review of current CAA practice at one of the core institutions charged with the development of the HELM project. At this university there are currently over 200 first year mathematics students and around 
600 first year engineering students, nearly all of whom experience the CAA system in their first year.

\section{The current situation at the institution under investigation}

In spite of the initial advantages that CAA system provided, the current situation is not so straightforward. Most classes are too large to be accommodated in one computer laboratory so some lecturers lack the resources to invigilate online summative tests. Some lecturers are concerned that the questions do not fully cover all aspects of a developing syllabus; and the time and learning requirements to develop new questions are prohibitive. For some, the existing questions are too focussed on testing the students' ability to carry out procedures, rather than exploring conceptual understanding.

These problems and others suggest that lecturers might not be able to teach according to their pedagogical ideals. Engeström (2000) suggested that such contradictions drive actions towards an "expansive solution” (p.966). However, while Engeström envisaged a collaborative and coordinated response from a body of practitioners, this has not happened since lecturers may respond to their own teaching needs.

This paper examines the lecturers' experiences of the use of the CAA system: the problems they have faced; how they have sought to mitigate the effects of these problems; current practice and how this has been shaped by these problems; and how they anticipate using CAA in the future. Thus we ask the following research questions:

RQ1. How is the CAA system implemented in first year mathematics modules for mathematics and engineering students at this university?

RQ2. Why are lecturers using CAA?

RQ3. What are lecturers' perceptions of issues arising?

RQ4. How are lecturers dealing with these issues?

\section{Method of investigation}

All thirteen lecturers of first year mathematics modules were approached to complete a questionnaire. Four lecturers reported they did not use the CAA system; the remaining nine returned completed questionnaires.

The first half of the questionnaire was aimed at addressing RQ1. Each lecturer was asked how the CAA system was implemented and delivered to students, covering the availability of practice tests, the format of the coursework tests, the type of feedback provided, whether the test is online or paper-based and the policy on collaboration between students. The second half of the questionnaire focussed on RQ2, asking lecturers what the CAA system assesses, the reasons for using CAA and the authoring of new questions.

Six of the nine lecturers that completed the questionnaire indicated they would be willing to take part in follow-up interviews. The first author conducted semi-structured interviews with these six lecturers (denoted hereafter as P1 to P6), which lasted between 27 minutes and 54 minutes. The interviews elaborated on the responses lecturers gave in 
the questionnaires, and explored lecturers' perceptions of the issues arising (RQ3) and how they are dealing with those issues (RQ4).

We present the findings of both the questionnaires and the interviews by considering each research question in turn.

\section{Lecturers' implementation of CAA}

All nine lecturers use the CAA system's practice tests with their students. Seven lecturers use CAA for the online summative test: of the remaining two, one tests students using paper-based tests and, for the other, the CAA practice tests are not followed by an analogous coursework test.

Three of the seven lecturers that use the CAA system's coursework tests invigilate the test in a computer lab; and the paper test is invigilated in a lecture theatre. The remaining four lecturers allow the students to conduct the coursework tests at the location and time of their choosing within a specified time period (usually two or three days).

The availability of practice tests before and after coursework tests differed substantially between lecturers. Of the seven groups of students that perform coursework tests online, three groups were permitted to access the practice tests after the coursework test was complete and four could not. How long practice tests are available to students before the online coursework test also varied between lecturers.

\section{Why lecturers use CAA}

In the questionnaire, the lecturers were presented with nine reasons for using CAA with which they could agree or disagree on a 5-point Likert scale. There was strong agreement that CAA frees up time, is convenient, provides opportunities and motivation for students to practise and provides immediate feedback. However, it is also evident that lecturers did not universally believe that the feedback the CAA system offers is reason enough to use it (one lecturer strongly agreed with the statement "students receive good quality feedback from the CAA system" as a reason for using it; three agreed; three neither agreed nor disagreed; and two disagreed).

The reasons for using CAA were discussed further in the interviews and four prominent themes emerged.

All six of the interviewed lecturers say they use the CAA system because previous lecturers of the modules have used it, thus it has become established practice. Inheritance was a common theme in the interviews: "that's what I inherited" (P3); "I've inherited it that way" (P4); "I've inherited it with the Calculus module that was taught previously” (P6).

The participants explained they have had informal discussions with colleagues on the topic of CAA; however, the effect of these discussions on the use of the CAA system differs between lecturers. Some lecturers believe that the departmental influence was an intrinsic reason for using CAA: "I use it because I've been told to use it" (P5); "I 
suppose [these discussions] have been a strong influence, because I hadn't used it before" (P1). On the other hand, one lecturer replied, "Not much" (P4), when asked how much influence discussions with other lecturers have had on the use of CAA.

Lecturers are keen not to spend an inordinate amount of their time on assessment, given the demands of assessing groups as large as 230 students: "If I'm going to consider a written piece of assessment... there's too much marking involved" (P5). The CAA system not only marks and provides feedback instantly - it also handles the distribution of the assessment, saving time: "it certainly frees up your time; it's convenient” (P3).

CAA can also be used as a tool to foster student responsibility and maturity for learning at university level. Lecturers said: "[With CAA] they have to take a strong degree of responsibility for their own learning" (P1); "with the computer tests, I think you encourage them to go and do some work" (P2). Another lecturer reported that students seem to accept this responsibility, supported by checking the access data: "it turns out they do this [the practice tests] quite a bit... For me it was a surprisingly high average of how many times students do these tests” (P4).

\section{Lecturers' perceptions of issues arising}

Though four key themes emerged as reasons to use CAA - continuing established practice, departmental influence, saving time and fostering student responsibility - the lecturers acknowledged that there have been issues.

The lecturers disagreed when asked whether the CAA system questions provide sufficient challenge to students (two believe they do; five believe they do not; two neither agree nor disagree). Most lecturers feel that the CAA system is most effective at testing procedural ability - "it's quite effective at making sure that they can carry out the procedures" (P6) - but there is less scope for testing conceptual understanding and recall: "I don't think it tests their recall, because they can have all their materials in front of them" (P6).

In order to test recall, it would be desirable to invigilate students as they attempt the summative test. However, while CAA is effective for assessing large groups of students, accommodating large cohorts in a single computer laboratory is not possible. To overcome this, four of the lecturers give students much more freedom over their environment and timing when performing the practice tests and summative test. For these students, lecturers cannot be sure how the test was completed: "how do you know who's done it? How do you know that they've done it on their own? How do you know if they've copied from somebody else or from the book?” (P1).

New questions would be needed to assess conceptual understanding. However, only three of the lecturers have attempted to do this; of which only one felt doing so was worthwhile. Of the lecturers that had not attempted to write new questions, only one believed it would be worthwhile learning how to do so. Although some lecturers would be confident in developing questions that suit the system, learning how to develop such questions for the system is time-consuming and consequently judged that it was not worth such effort. One lecturer explained: "There is a system where you can write your 
own questions, but that is a lot of work. I think it's five hours for one question, and you really have to learn the system” (P5).

The issues that lecturers have encountered are often attributed to the age of the system: "this is such an antiquated system" (P4), for example. While some lecturers are keen to move onto another system, the existing bank of questions remains a treasured resource: "if we use something else, then that means we've got to leave behind the question bank that we're using” (P6). Instead, lecturers have adjusted their practices in order to mitigate the effect of these issues.

\section{How lecturers deal with CAA issues}

The issues that lecturers have identified while using CAA cause potential conflicts. For example, a lecturer may want to assess students' deeper understanding, though it seems that CAA does not test students' conceptual understanding so well. Such conflicts give scope for change (Engeström 2000).

In this case, some of the lecturers in our study have accommodated other assessment techniques in their modules that they believe better test conceptual understanding. Lecturers use coursework and projects to explore the grasp of underlying concepts, while exams cover aspects of recall, procedural ability and conceptual understanding. The CAA system remains a useful tool for testing procedural knowledge: "[CAA] is quite effective at making sure that they can carry out the procedures... I just test the procedures through computer courseworks, and I test the conceptual things through written courseworks" (P6).

A consequence of these adjustments is that the weighting of existing assessments had to be changed in order to accommodate new assessments. Indeed, the allocation of module scores given to CAA decreased in some modules: "we actually restructured the whole assessment and reduced the number of CAAs and also the weighting, because the coursework then took that weighting away” (P5).

The low weighting of the CAA component across these modules also mitigates the problem of not being able to invigilate students' attempts at the summative test. The impact of cheating is small — "For 2.5\%, I just don't think it's worth putting up a major police operation to find out what students really do" (P4) - and lecturers are more concerned that students are motivated to practise for and complete these assessments: "I'm not sufficiently worried about it to really make my own life and theirs [the students'] much more difficult by starting to run it as an invigilated test” (P3).

Lecturers still have misgivings about the CAA system. One described the system as "poor quality" (P3) due to its age and other lecturers tended to agree; though they acknowledge that, for some things, CAA is "good" (P5). Further change of the assessment structure is not anticipated: rather, any development in CAA would be of the system: "I guess it's only a matter of time before we get some other kind of system, which will undoubtedly do some things better” (P3). 


\section{Discussion}

This study of the use of computer-aided assessment by lecturers has identified a number of dilemmas that lecturers face. Furthermore, it has highlighted the means by which these lecturers have addressed these issues and why they continued to use the CAA system with their students.

- CAA saves time in compiling, distributing and marking assessments. This is particularly advantageous with large student groups. Some aspects of the CAA system are less efficient, however: developing new questions remains a challenge and is not considered worthwhile.

- The large question bank is considered a valuable resource and ensures that compiling assessments remains efficient. However, lecturers feel that there are aspects of students' understanding that are untested by the CAA system and students are not sufficiently challenged. Lecturers have made use of other assessment techniques in order to acquire a more rounded understanding of their students’ progress.

- By giving students a routine of practising before a test, it allows them to develop a mature and independent approach to their learning. In large groups, where summative tests are not invigilated, there is a threat that students could abuse this freedom. In response, the CAA summative tests matter less towards the overall module work - and despite this, students remain motivated to complete the tests.

The lecturers in this study believed that the advantages that CAA gave them are greater than the disadvantages. The disadvantages were such that the lecturers had to make compromises: there remained contradictions between lecturers' pedagogical ideals and the practice they were able to employ.

Of great disadvantage to the lecturer is that the CAA system does not test all aspects of a student's understanding of mathematical topics. The result is that lecturers have had to adopt other, more time-consuming assessment techniques.

The lecturers' responses raised questions on the aims of assessment and whether the CAA system satisfied those aims. It would seem, from their responses, that the CAA system satisfied some aims - it provided opportunities for students to receive regular, timely feedback and reduced the time burden on the lecturers - yet it did not fulfil every requirement.

The fact that the CAA system did not satisfy the lecturers' every need for assessment leads us to wonder what effect this has on students' learning. The lecturers offered their insights on what they regarded to be the strongest and weakest aspects of the CAA system for learning.

Of its strengths, the lecturers noted that students were sufficiently motivated to use the practice test facility in order to maximise their mark yield. Lecturer P5 noted that students were under pressure to get high marks "in a time of high unemployment, even 
for graduates" (P5). The practice tests offered the opportunity for students to become familiar with the material before taking the summative test. By giving students the freedom and the opportunity to practise, the lecturers felt that it fostered a more responsible and autonomous approach in students towards their own learning and progress.

Lecturers P1 and P2 noticed this effect with their students, whose students requested access to the practice tests prior to the final examinations. These students felt that the practice tests were a useful revision tool that they could use autonomously to self-assess whether they had learned the material sufficiently and gain feedback.

There are some caveats, however. The lecturers disagreed on the suitability of the feedback that is given to students. One lecturer felt that the lack of a system to provide individualised feedback meant that it offered nothing better than what is already in lecture notes or textbooks (P4). Some other lecturers also felt the feedback gave too much direction to students; one noted that students were inclined to learn the procedure given in the feedback, which would often be context-dependent - "if you give them the same question with simple changes, they cannot do it" (P2).

\section{Concluding remarks}

The lecturers indicated that the CAA system provided a useful, timesaving assessment tool that gave students the opportunity to practise their mathematical skills between lectures and receive immediate feedback. However, the lecturers were concerned that the CAA system lacked the capability of testing students' conceptual understanding.

By not testing the conceptual understanding of students, the CAA system causes two problems: it does not provide lecturers with knowledge of these aspects of their students' progress; and the students that wish to test this aspect of their learning cannot use the CAA system to do so. Although the lecturers reported that they use other assessment techniques to overcome this issue, it is clear that they would desire the option to test conceptual understanding in future developments of CAA.

The lecturers' responses indicate that CAA is likely to be most beneficial as a tool for ensuring that students can carry out standard procedures. On the other hand, the lecturers also suggested that CAA is less effective for providing feedback and for testing students' conceptual understanding.

\section{References}

Bull, J. and McKenna, C. (2003) Blueprint for computer-assisted assessment. London: RoutledgeFalmer.

Conole, G. and Warburton, B. (2005) A review of computer-assisted assessment. Research in Learning Technology, 13(1): 17-31.

Engeström, Y. (2000) Activity theory as a framework for analyzing and redesigning work. Ergonomics, 43(7): 960-974.

Gill, M. and Greenhow, M. (2008) How effective is feedback in computer-aided assessments? Learning, Media and Technology, 33(3): 207-220. 
Harrison, M.C., Green, D.R., Pidcock, D. and Palipana, A.S. (2007) HELM educational transfer. MSOR Connections, 7(1): 20-22.

HELM (2006) HELM - Helping Engineers Learn Mathematics. Available at http://helm.lboro.ac.uk [Accessed 30 April 2012].

Miller, T. (2009) Formative computer-based assessment in higher education: the effectiveness of feedback in supporting student learning. Assessment and Evaluation in Higher Education, 34(2): 181-192.

Sangwin, C. (2006) Assessing elementary algebra with STACK. International Journal of Mathematical Education in Science and Technology, 38(8): 987-1002. 